\title{
Carotid arterial stiffness and intima-media thickness: A little impact of uric acid
}

\author{
Michael Y Henein ${ }^{1,2,3}$, Federico Vancheri ${ }^{4}$ \\ ${ }^{1}$ Institute of Public Health and Clinical Medicine, Umea University, Sweden; ${ }^{2}$ Brunel University, Middlesex, UK; \\ ${ }^{3}$ St George's University London3, UK; ${ }^{4}$ Internal Medicine, S. Elia Hospital, Caltanissetta, Italy
}

Accurate assessment of cardiovascular (CV) risk is essential for clinical decision making. Serum uric acid (UA) has been proposed as a novel additional $\mathrm{CV}$ risk [1,2]. UA is the normal end product of purine metabolism arising from dietary and endogenous nucleic acid [3]. In the early ' 80 s it was considered a powerful antioxidant, protecting against the effects of aging and cancer, due to a beneficial evolutionary loss of uricase activity in hominoids [4]. More recently, laboratory and epidemiological investigations have suggested elevated UA to be associated with atherosclerosis and CV events [5-9]. However, this relationship remains controversial [10] and serum UA is not listed as CV risk factor in the guidelines on $\mathrm{CV}$ disease prevention $[11,12]$.

Possible underlying pathophysiological mechanisms behind the relationship between UA and subsequent coronary and cerebrovascular events include endothelial dysfunction, vascular smooth muscle proliferation and activation of inflammatory cells, all of which are affected by UA and involved in the development of atherosclerosis [13-16]. They reduce the elastic properties of the arterial wall, induce smooth muscle hypertrophy and intimal thickening, thus leading to increased arterial stiffness, carotid intima-media thickening, arterial plaque formation and coronary calcification [17-20]. These changes may occur even in the absence of clinical manifestations of disease and can be assessed at early stages by non-invasive techniques.

In the present issue of the Monaldi Archives of Chest Disease, Francesco Antonini-Canterin et al. [21] report a study investigating the carotid ultrasound assessment of UA effect on carotid beta stiffness index (BSI) and intima-media thickness (CIMT). In a

Correspondence: Michael Henein, Professor of Cardiology, Institute of Public Health and Clinical Medicine, Umea University, 90187 Umea, Sweden.

E-mail: michael.henein@umu.se

Key words: Cardiovascular risk; uric acid; beta stiffness index; intima-media thickness.

Received for publication: 4 March 2019

Accepted for publication: 5 March 2019.

(C) Copyright M. Y Henein and F. Vancheri, 2019

Licensee PAGEPress, Italy

Monaldi Archives for Chest Disease 2019; 89:1057

doi: 10.4081/monaldi.2019.1057

This article is distributed under the terms of the Creative Commons Attribution Noncommercial License (by-nc 4.0) which permits any noncommercial use, distribution, and reproduction in any medium, provided the original author(s) and source are credited. large sample of patients with high CV risk but no history of coronary artery disease, heart failure or cardiomyopathies, with normal or elevated UA levels, the authors found a significant correlation between UA levels and BSI and CIMT. However, the correlation coefficients were small with large dispersion of data as evidenced in the scatterplots. Moreover, when traditional CV risk factors for atherosclerosis, such as age, glycemia, blood pressure, LDL-cholesterol, were adjusted for in a multivariate regression analysis, the single risk factor with the largest statistical significance was age, whereas UA had only marginal significance.

The results of this study highlight some inconsistencies in the relationship between UA and CV risk prediction. Age is associated with arterial stiffness, similar to that observed in atherosclerosis $[22,23]$. In addition, age is associated with higher serum UA levels [10] and with most CV risk factors. The multivariate regression analysis in the present paper shows that BSI and CIMT are significantly related to age, but not to the other established risk factors and only marginally to UA levels. This indicates that age is a confounder and the relationship of BSI and CIMT with the traditional risk factors and UA is not significant or negligible because they have been adjusted for.

This reasoning is in line with previous studies in showing that when the traditional CV risk factors were adjusted for in the multivariate analysis, the relationship between serum UA levels and CIMT or arterial stiffness became weak or lost significance [24-26] In general, the statistical association between UA and CV risk is inversely proportional to the number of covariates included in the regression model [27]. Accordingly, since UA is associated with the risk factors for atherosclerosis, it seems that the relationship between high serum UA and early measures of atherosclerosis may be due to its relationship with risk factors, particularly with age.

Furthermore, two large meta-analyses showed no significant trend in the dose-response relationship between serum UA levels and $\mathrm{CV}$ risk, and in the relationship between UA levels reduction from baseline to the end of follow-up and CV clinical events [28,29].

Thus, despite several reports of positive correlation of serum UA and subsequent CV events, the above observations suggest that serum UA does not fulfill some of the criteria to be considered a novel CV risk with an incremental value in providing predictive information above those provided by the well established risk factors in guiding treatment [30].

\section{References}

1. Bellasi A, Raggi P. Among markers of risk, uric acid remains a two-faced Janus awaiting definitive framing. Atherosclerosis 2018;272:219-21. 
2. Muiesan ML, Agabiti-Rosei C, Paini A, Salvetti M. Uric acid and cardiovascular disease: An update. European cardiology 2016;11:54-9.

3. So A, Thorens B. Uric acid transport and disease. J Clin Invest 2010;120:1791-9.

4. Ames BN, Cathcart R, Schwiers E, Hochstein P. Uric acid provides an antioxidant defense in humans against oxidant- and radical-caused aging and cancer: a hypothesis. Proc Natl Acad Sci USA1981;78:6858-62.

5. Zhao J, Chen H, Liu N, et al. Role of hyperhomocysteinemia and hyperuricemia in pathogenesis of atherosclerosis. J Stroke Cerebrovasc Dis 2017;26:2695-9.

6. Baker JF, Krishnan E, Chen L, Schumacher HR. Serum uric acid and cardiovascular disease: Recent developments, and where do they leave us? Am J Med 2005;118:816-26.

7. Chen $\mathrm{Y}, \mathrm{Xu} \mathrm{BH}$, Sun WW, et al. Impact of the serum uric acid level on subclinical atherosclerosis in middle-aged and elderly Chinese. J Atheroscler Thromb 2015;22:823-32.

8. Yang X, Lv H, Hidru TH, et al. Relation of serum uric acid to asymptomatic proximal extracranial artery stenosis in a middle-aged Chinese population: a community-based cross-sectional study. BMJ Open 2018;8:e020681.

9. Wang R, Song Y, Yan Y, Ding Z. Elevated serum uric acid and risk of cardiovascular or all-cause mortality in people with suspected or definite coronary artery disease: A meta-analysis. Atherosclerosis 2016;254:193-9.

10. Wu AH, Gladden JD, Ahmed M, Ahmed A, Filippatos G. Relation of serum uric acid to cardiovascular disease. International Journal of Cardiology 2016;213:4-7.

11. Piepoli MF, Hoes AW, Agewall S, et al. 2016 European Guidelines on cardiovascular disease prevention in clinical practice. The Sixth Joint Task Force of the European Society of Cardiology and Other Societies on Cardiovascular Disease Prevention in Clinical Practice. Eur Heart J 2016;37:2315-81.

12. Greenland P, Alpert JS, Beller GA, et al. 2010 ACCF/AHA Guideline for Assessment of Cardiovascular Risk in Asymptomatic Adults: A Report of the American College of Cardiology Foundation/American Heart Association Task Force on Practice Guidelines. J Am Colle Cardiol 2010;56:e50-e103.

13. Khosla UM, Zharikov S, Finch JL, et al. Hyperuricemia induces endothelial dysfunction. Kidney Intern 2005;67:1739-42.

14. Corry DB, Eslami P, Yamamoto K, et al. Uric acid stimulates vascular smooth muscle cell proliferation and oxidative stress via the vascular renin-angiotensin system. J Hypertens 2008;26:269-75.

15. Zhen HT, Gui F. The role of hyperuricemia on vascular endothelium dysfunction. Biomed Rep 2017;7:325-30.

16. Ruggiero C, Cherubini A, Ble A, et al. Uric acid and inflammatory markers. Eur Heart J 2006;27:1174-81.

17. Zieman SJ, Melenovsky V, Kass DA. Mechanisms, pathophys- iology, and therapy of arterial stiffness. Arterioscler Thromb Vasc Biol2005;25:932-43.

18. Naqvi TZ, Lee M-S. Carotid intima-media thickness and plaque in cardiovascular risk assessment. JACC Cardiovasc Imaging 2014;7:1025-38.

19. Nicoll R, Henein MY. Arterial calcification: Friend or foe? Int J Cardiol 2013;167:322-7.

20. Krishnan E, Pandya BJ, Chung L, Dabbous O. Hyperuricemia and the risk for subclinical coronary atherosclerosis - data from a prospective observational cohort study. Arthritis Res Ther 2011;13:R66.

21. Antonini-Canterin F, Di Nora C, Pellegrinet M, et al. Effect of uric acid serum levels on carotid arterial stiffness and intimamedia thickness: A high resolution Echo-Tracking Study. Monaldi Arch Chest Dis 2019;89:1007.

22. Veerasamy AM, Ford AG, Neely AD, et al. Association of aging, arterial stiffness, and cardiovascular disease: A review. Cardiol Rev 2014;22:223-32.

23. Kim HL, Lim WH, Seo JB, et al. Association between arterial stiffness and left ventricular diastolic function in relation to gender and age. Medicine (Baltimore) 2017;96:e5783.

24. Iribarren C, Folsom AR, Eckfeldt JH, et al. Correlates of uric acid and its association with asymptomatic carotid atherosclerosis: The ARIC study. Ann Epidemiol 1996;6:331-40.

25. Wijnands JMA, Boonen A, van Sloten TT, et al. Association between serum uric acid, aortic, carotid and femoral stiffness among adults aged 40-75 years without and with type 2 diabetes mellitus: The Maastricht Study. J Hypertens 2015;33: 1642-50.

26. Kim SY, Guevara JP, Kim KM, et al. Hyperuricemia and coronary heart disease: A systematic review and meta-analysis. Arthritis Care Res (Hoboken) 2010;62:170-80.

27. Battaggia A, Scalisi A, Puccetti L. Hyperuricemia does not seem to be an independent risk factor for coronary heart disease. Clin Chem Lab Med 2018;56:e59. Comment in: Braga F, Ferrara S, Pasqualetti S, Panteghini M. Hyperuricemia does not seem to be an independent risk factor for coronary heart disease. Clin Chem Lab Med 2018;56:e63-e4.

28. Li M, Hu XL, Fan YL, et al. Hyperuricemia and the risk for coronary heart disease morbidity and mortality a systematic review and dose-response meta-analysis. Sci Rep 2016;6: 19520.

29. Savarese G, Ferri C, Trimarco B, et al. Changes in serum uric acid levels and cardiovascular events: A meta-analysis. Nutr Metab Cardiovasc Diss 2013;23:707-14.

30. Hlatky AM, Greenland KP, Arnett MD, et al. Criteria for evaluation of novel markers of cardiovascular risk: A scientific statement from the American Heart Association. Circulation 2009;119:2408-16. 